\section{COVER FEATURES}

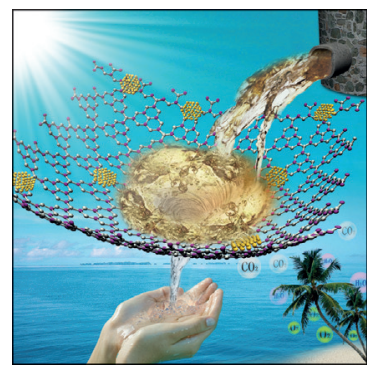

Under the visible light irradiation, layer-contacted graphene-like (GL)- $\mathrm{MoS}_{2} / \mathrm{C}_{3} \mathrm{~N}_{4}$ composites can turn domestic wastewater and industrial sewage into clean water that can be discharged into the environment. GL-MoS $/ \mathrm{C}_{3} \mathrm{~N}_{4}$ are low cost and highly efficient photocatalytic materials for the degradation of pollutants. This shows how human beings can possess the wisdom and power for solving environmental problems and creating a beautiful world by our own hands. More information can be found in the Full Paper by H. Xu, H. Li et al. on page $4764 \mathrm{ff}$.

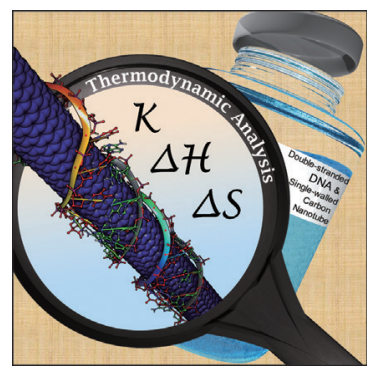

A magnifying glass, in which one can see a nanohybrid that was formed by a double-stranded DNA and singlewalled carbon nanotube in water to which thermodynamic analysis was applied to obtain the binding constant $(K)$, $\Delta H$, and $\Delta S$ values. More information can be found in the Full Paper by N. Nakashima, et al. on page $4774 \mathrm{ff}$.

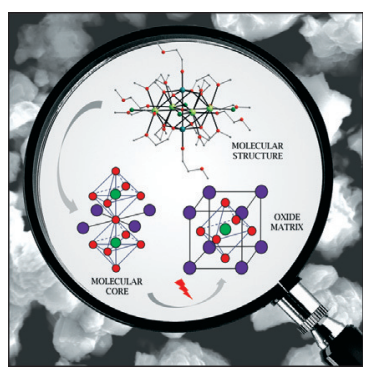

Oxide nanomaterials with interesting properties have various applications, including efficient oxide lattices for luminescent ions. This wide range of applications creates a strong impetus for new and inexpensive methods for their synthesis. Of the new preparation techniques are those involving metal alkoxides with strictly defined metal stoichiometries at the molecular level, which fulfill the requirements for sophisticated binary oxides including perovskites, such as Group 2 zirconates. More information can be found in the Full Paper by P. Sobota, et al. on page $4780 \mathrm{ff}$.

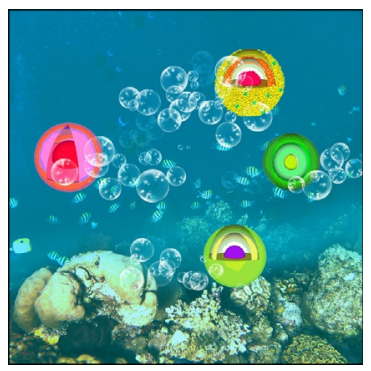

Bubble-propelled $\mathrm{Fe}^{0}$ Janus nanomotors show their potential as decontamination agents of pollutants in Indonesian coral reefs. Enhanced pollutant decomposition triggered by biocompatible $\mathrm{Fe}^{0}$ motors, which can be handled in air and fabricated in ton quantities for a low cost, will revolutionize the way the environmental remediation is carried out. More information can be found in the Full Paper by M. Pumera et al. on page $4789 \mathrm{ff}$.

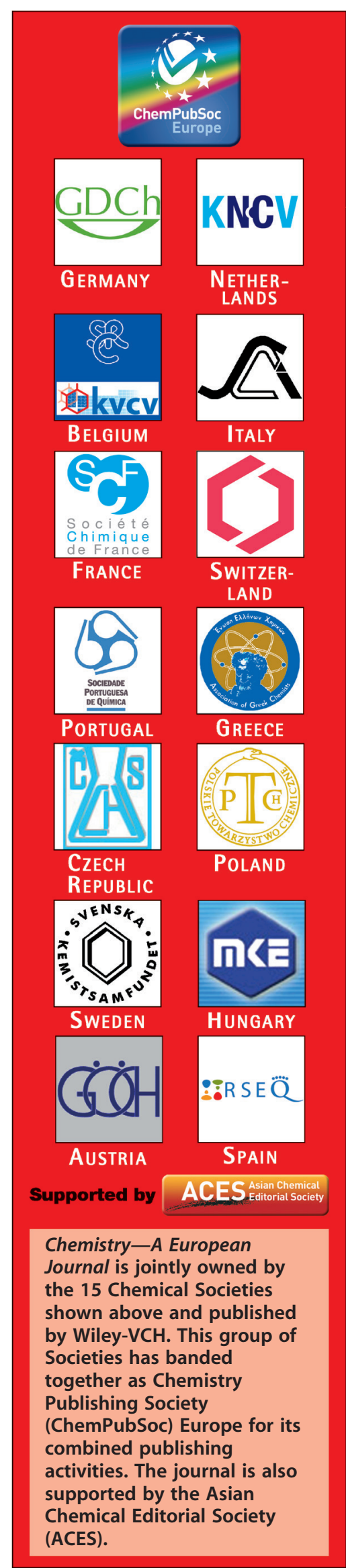




\section{FEATURED ARTICLES}

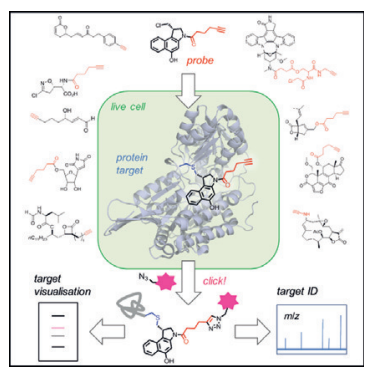

\section{Bioorthogonal Tags}

The identification of protein interacting partners can be achieved by the functionalization of a bioactive small molecule of interest using alkynes. Specifically terminal alkynes are widely used and robust bioorthogonal tags for click reactions. The challenges of synthesizing such a functionalized probe are described in the Concept article by S. A. Sieber et al. on page $4666 \mathrm{ff}$.

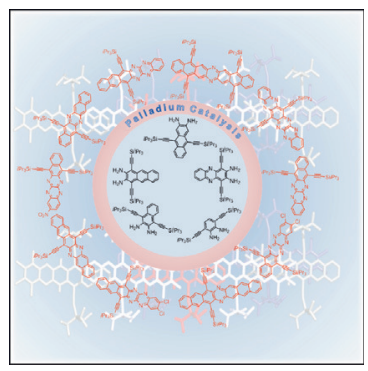

\section{Palladium Catalysis}

In their Concept on page 4680 ff., U. H. F. Bunz and J. U. Engelhart discuss the Pd-catalyzed assembly of azaacenes with otherwise difficult to obtain substitution patterns. Pdcatalyzed coupling of aromatic dihalides to ortho-diaminoarenes furnishes embedded stable $N, N^{\prime}$-dihydropyrazines expediently and in often excellent yields. The embedded $\mathrm{N}, \mathrm{N}^{\prime}$-dihydropyrazines can then be oxidized by $\mathrm{MnO}_{2}$ to give substituted azatetracenes, azapentacenes, azahexacenes, and azaheptacenes, which are soluble, processable, and stable. This powerful Pd-catalyzed methodology allows the preparation of azaacenes, including diaza-, tetraaza- and hexaazaacenes.

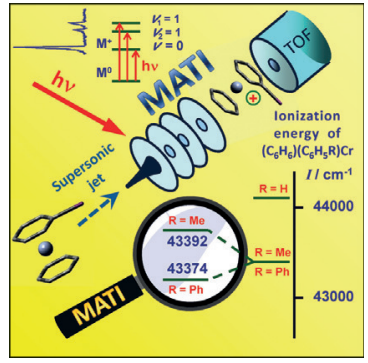

\section{Substituent Effects}

Transition metal bisarene compounds, like metallocenes, form one of the most interesting and intriguing families of organometallics. Mass-analyzed threshold ionization (MATI) spectra of jet-cooled $[(\mathrm{PhH})(\mathrm{PhR}) \mathrm{Cr}]$ complexes $(\mathrm{R}=\mathrm{Me}, \mathrm{Ph})$ reveal with unprecedented accuracy the effects of methyl and phenyl groups on the electronic structure of bis(benzene)chromium. These "pure" substituent effects provide new insights into the changes in electronic structure caused by the mutual substituent influence in bisarene complexes. For more details, see the Communication by S. Ketkov et al. on page $4690 \mathrm{ff}$.

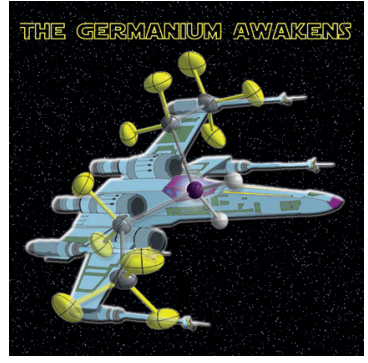

\section{Main-Group Chemistry}

The germanium awakens in the field of bis(pentafluoroethyl)germanes. Employing the phenyl group as a protecting group opens a straightforward synthetic route to $\left(\mathrm{C}_{2} \mathrm{~F}_{5}\right)_{2} \mathrm{GePh}_{2}$. To obtain functionalizable bis(pentafluoroethyl)germanes, the deprotection can be effected with gaseous $\mathrm{HBr}$ or $\mathrm{HCl}$ under the assistance of a Lewis acidic catalyst. The derivatization of the obtained halogenogermanes is described by the reactions with $\mathrm{Ag}_{2} \mathrm{CO}_{3}$ to obtain hexakis(pentafluoroethyl)trigermoxane and with $\mathrm{Bu}_{3} \mathrm{SnH}$ yielding $\left(\mathrm{C}_{2} \mathrm{~F}_{5}\right)_{2} \mathrm{GeH}_{2}$, studied by X-ray diffraction. The complete story can be found in the Full Paper by B. Hoge and colleagues on page $4758 \mathrm{ff}$. 
"It shows that human beings possess the wisdom and power for solving environmental problems, and also for creating a beautiful world by our own hands." Read more about the story behind the cover in the Cover Profile and about the research itself on page $4764 \mathrm{ff}$. (DOI: 10.1002/chem.201503660).

\section{COVER PROFILE}

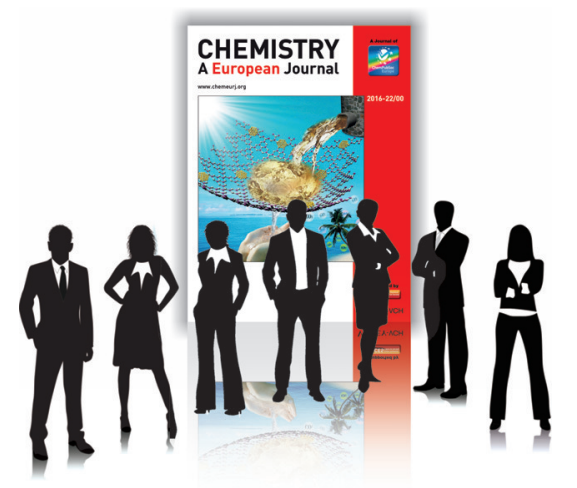

J. Yan, Z. Chen, H. Ji, Z. Liu, X. Wang, Y. Xu, X. She, L. Huang, L. Xu, H. Xu, * H. $L i^{*}$. 4645

Construction of a 2D Graphene-Like $\mathrm{MoS}_{2} / \mathrm{C}_{3} \mathrm{~N}_{4}$ Heterojunction with Enhanced Visible-Light Photocatalytic Activity and Photoelectrochemical Activity

CONCEPTS

Tiny tag: Terminal alkynes are widely used as robust bioorthogonal tags for click reactions. Functionalization of a bioactive small molecule of interest with an alkyne can enable the identification of its protein interacting partners (see figure). This Concept article focuses on the challenges of synthesizing such a functionalized probe.

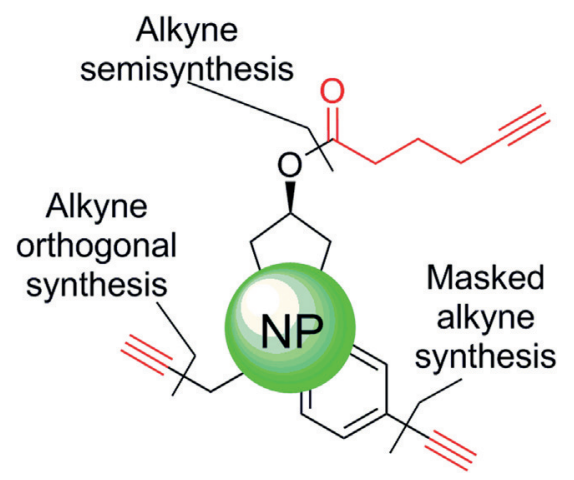<smiles>[Y6]c1cc2c([R])c(N)c(N)c([R])c2cc1C</smiles><smiles></smiles><smiles></smiles>

well for $N, N^{\prime}$-dihydropyrazines that are part of larger ( $\geq 4$ ring), linearly annulated dihydroacene types. Oxidation of these $N, N^{\prime}$-dihydropyrazines then gives azaacenes.
Palladium Catalysis

U. H. F. Bunz, * J. U. Engelhart 4680-4689

The Palladium Way to N-Heteroacenes
Palladium catalysis is a new and powerful way to construct azaacene frameworks. It allows coupling of aromatic ortho-diamines to aromatic orthodihalides, resulting in embedded $N, N^{\prime}$ dihydropyrazines. This reaction works
Chemical Biology

J. Lehmann, M. H. Wright,

S. A. Sieber* $4666-4678$

Making a Long Journey Short: Alkyne Functionalization of Natural Product Scaffolds

\section{COMMUNICATIONS}
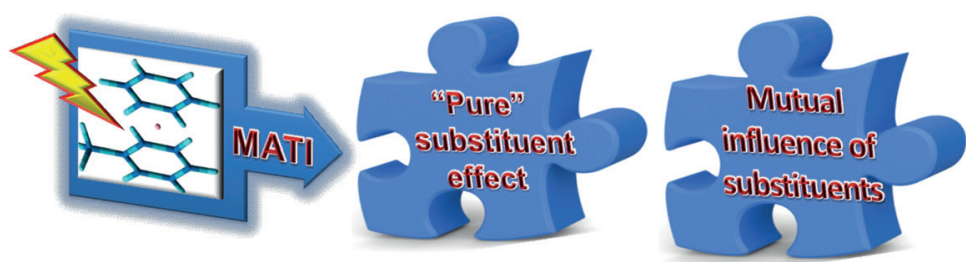

Our mutual influence: Mass-analyzed threshold ionization spectra of the chromium bisarene complexes bearing a toluene or biphenyl ligand reveal accurate contributions of a single methyl or phenyl group to changes in the ionization energy. Unprecedented resolution of the spectra provides new insights into the mutual influence of substituents in sandwich compounds.
Substituent Effects

S. Y. Ketkov, * G. V. Markin, S. Y. Tzeng, W. B. Tzeng * .................. 4690-4694

Fine Substituent Effects in Sandwich Complexes: A Threshold lonization Study of Monosubstituted Chromium Bisarene Compounds 


\section{Materials Science}

B. P. Biswal, H. D. Chaudhari, R. Banerjee,*

U. K. Kharul* $4695-4699$

Chemically Stable Covalent Organic Framework (COF)-Polybenzimidazole Hybrid Membranes: Enhanced Gas Separation through Pore Modulation

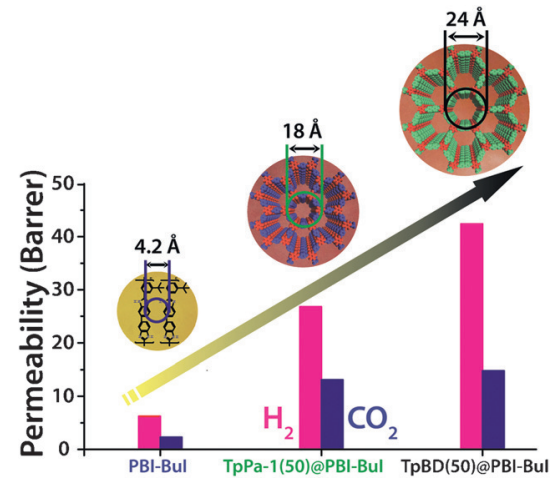

Pore form: Highly flexible, TpPa-1@PBIBul and TpBD@PBI-Bul hybrid membranes based on chemically stable covalent organic frameworks (COFs) were obtained. The loading was substantially higher $(50 \%)$ than generally observed with MOFs. These hybrid membranes show an enhancement in permeability with appreciable separation factors for $\mathrm{CO}_{2} / \mathrm{N}_{2}$ and $\mathrm{CO}_{2} / \mathrm{CH}_{4}$ (see figure). Further, it was found that with COF-pore modulation, the gas permeability can be systematically enhanced.

\section{EPR Spectroscopy}

S. Valera, K. Ackermann, C. Pliotas, H. Huang, J. H. Naismith,

O B. E. Bode* $4700-4703$

Accurate Extraction of Nanometer Distances in Multimers by Pulse EPR
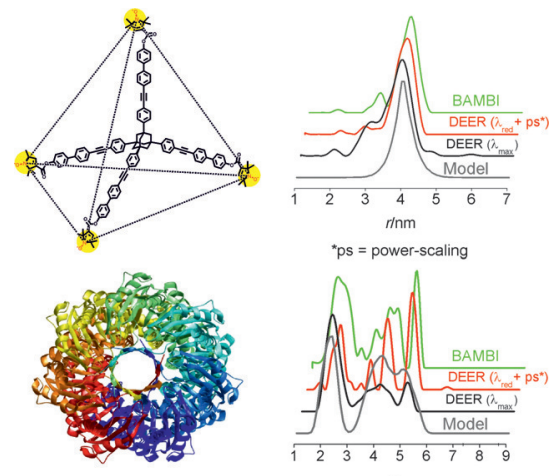

True distances even in multimers: Pulse EPR in complex biological samples is a powerful method to extract distances in the nanometer range. However, multimers present a major challenge for obtaining accurate distance information. In this paper, methods for effectively diminishing multi-spin effects are quantified without overly compromising on sensitivity in complex biological systems and validated on custom synthesized model compounds (see graphics).
Single-Molecule Magnets

Y.-S. Meng, Y.-S. Qiao, Y.-Q. Zhang,

S.-D. Jiang, Z.-S. Meng, B.-W. Wang, *

Z.-M. Wang, S. Gao*

$4704-4708$

Can Non-Kramers Tm"' Mononuclear Molecules be Single-Molecule Magnets (SMMs)?

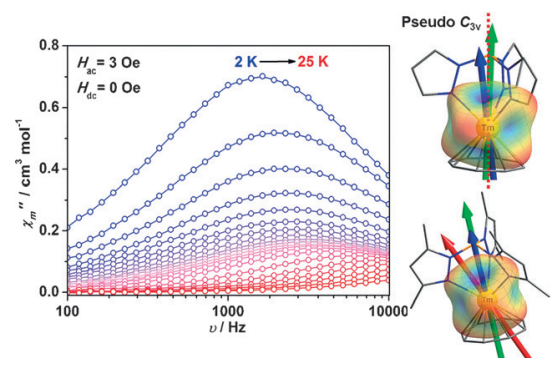

Two thulium mononuclear single-molecule magnets (SMMs) have been reported. [(Tp)Tm(COT)] (Tp = hydrotris(1-pyrazolyl)borate; $\mathrm{COT}=$ cyclooctatetraenide) possesses relatively high $U_{\text {eff }}$ $(111 \mathrm{~K})$ and exhibits zero-field slow magnetic relaxation after dilution. The origin of their magnetic properties was revealed by a detailed magnetic study and theoretical calculations (see figure).
Fused-Ring Systems

D. P. Sumy, N. J. Dodge, C. M. Harrison, A. D. Finke, A. C. Whalley*... 4709-4712

Tridecacyclene: A Cyclic Tetramer of Acenaphthylene

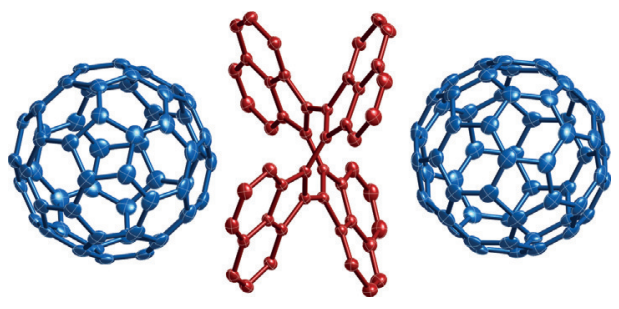

What a catch! A cyclic tetramer of acenaphthylene was synthesized in a single step. The compound exhibits interesting electronic and structural properties when compared to the better-known cyclic trimer due to the presence of a central eight-membered ring. The saddle-like shape of cyclic tetramer allows it to form cocrystalline supramolecular assemblies with $C_{60}$ in the solid state (see scheme). 
The SQ-ILs to pay the bills: Three novel hybrid ionic liquids based on cage silsesquioxane (SQ) were rapidly prepared in high yields by the photochemical thiol-ene reaction. They could further self-assemble into perfect vesicles with "yolk-shell" structures. These SQ-based ILs exhibited low glass transition temperatures and good thermal stability.

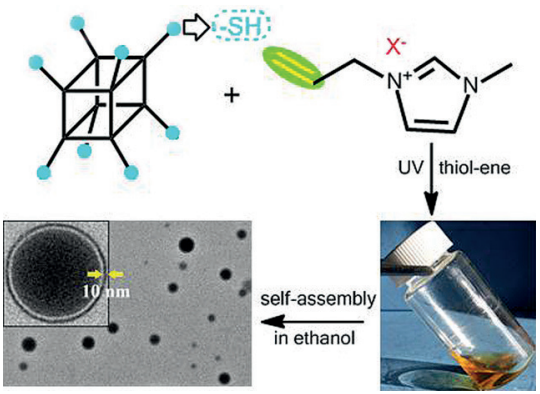

Ionic Liquids

L. Li, H. Liu* $4713-4716$

Rapid Preparation of SilsesquioxaneBased Ionic Liquids
Charge-transfer interactions are introduced to the perylenediimide framework and lead to rapid intersystem crossing to yield ${ }^{3} \mathrm{PDI}^{*}$, providing a stuctural alternative for optoelectronic applications (see figure).
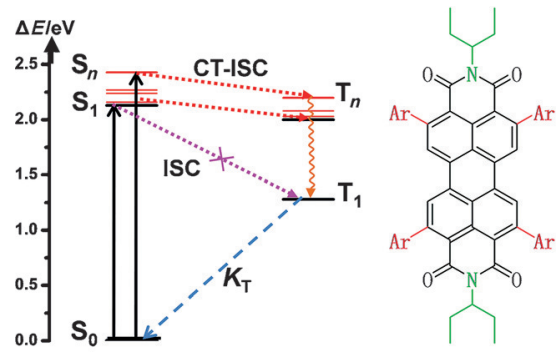

Organic Electronics

Z. Yu, Y. Wu, ${ }^{*}$ Q. Peng, C. Sun, J. Chen, J. Yao, H. Fu* $4717-4722$

Accessing the Triplet State in HeavyAtom-Free Perylene Diimides
The crystalline sponge method provides conclusive proof of the stereospecific addition in the metal-free diboration of internal aliphatic alkenes (see scheme). The compatibility of common boryl groups with a monoporous $\mathrm{Znl}_{2}$ network gives access to the crystal structures of the oily organoborane compounds. The relative stereochemistry of the metal-free diboration products was unequivocally assigned and fully consistent with the DFT calculations.

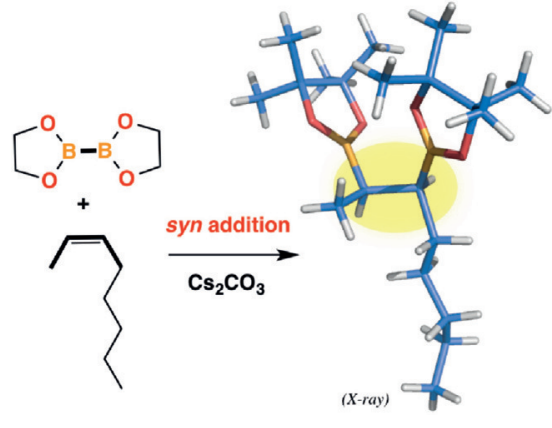

Organocatalysis

A. B. Cuenca, N. Zigon, V. Duplan,

M. Hoshino, M. Fujita, *

E. Fernández*

$4723-4726$

Undeniable Confirmation of the synAddition Mechanism for Metal-Free Diboration by Using the Crystalline Sponge Method

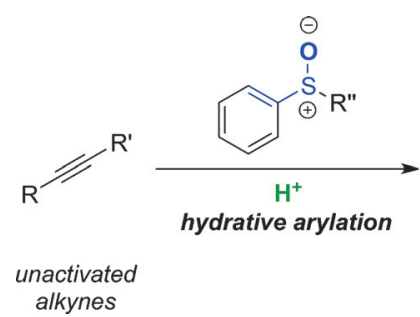

Two in one! A one-pot procedure has been developed for the synthesis of $\alpha$-arylated carbonyl compounds using a Brønsted acid-mediated reaction of unactivated alkynes with aryl sulfoxides
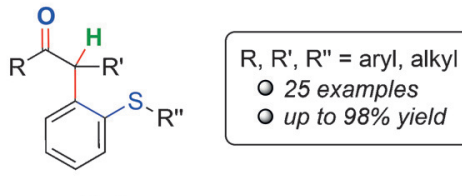

$\alpha$-aryl ketones

(see scheme). The products were obtained in high yields and bear useful synthetic handles for further functionalization.

\section{Synthetic Methods}

D. Kaiser, L. F. Veiros,

N. Maulide* $4727-4732$

Brønsted Acid-Mediated Hydrative Arylation of Unactivated Alkynes 


\section{Asymmetric Catalysis}

D. Du, Q. Xu, X.-G. Li, M. Shi* 4733-4737

Construction of Spirocyclic Oxindoles through Regio- and Stereoselective $[3+2]$ or $[3+2] /[4+2]$ Cascade Reaction of $\alpha, \beta$-Unsaturated Imines with 3-Isothiocyanato Oxindole

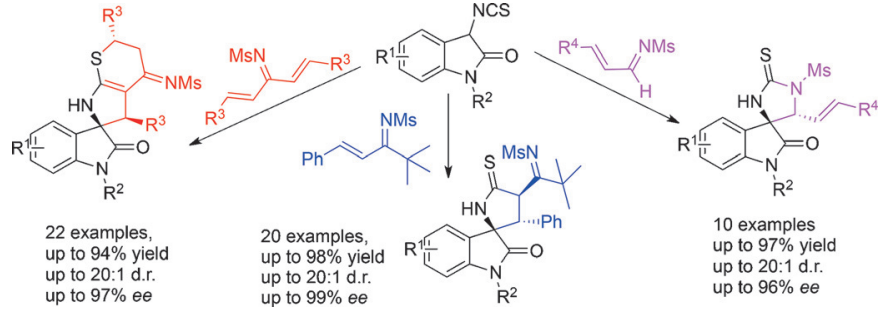

Spiro synthesis: Construction of spirocyclic oxindoles through regio- and stereoselective $[3+2]$ or $[3+2] /[4+2]$ cas- cade reaction of $\alpha, \beta$-unsaturated imines with 3-isothiocyanato oxindoles has been reported (see scheme).

\section{Synthetic Methods}

W. J. Kerr, ${ }^{*}$ R. J. Mudd,

J. A. Brown $4738-4742$

Iridium(I) N-Heterocyclic Carbene (NHC)/Phosphine Catalysts for Mild and Chemoselective Hydrogenation Processes
Dolvent $\underset{20.1 \mathrm{M}), \mathrm{H}_{2}(1 \mathrm{~atm}),}{25^{\circ} \mathrm{C}, 2 \mathrm{~h}}$

$\mathrm{DG}=$ ketone, ester, amide, acid, nitro, vinyl ether Chemoselective hydrogenation processes Wide applicable solvent range
The directed, chemoselective hydrogenation of olefins has been established by using iridium(I) catalysts, which feature a tuned $\mathrm{NHC}$ /phosphine ligand combination. This selective reduction process has been demonstrated in a wide array of solvents, including more environmentally acceptable media, also allowing further refinement of hydrogenation selectivity (see scheme; $D G=$ directing group).
Density Functional Calculations

C. E. Kefalidis, ${ }^{*}$ L. Maron* ... $4743-4747$

Insights into the Cascade Reaction of $\mathrm{CO}$ and Heteroallenes Mediated by Dinitrogen Hafnocene Complexes: The Indirect Effect of Nitride's Nucleophilicity

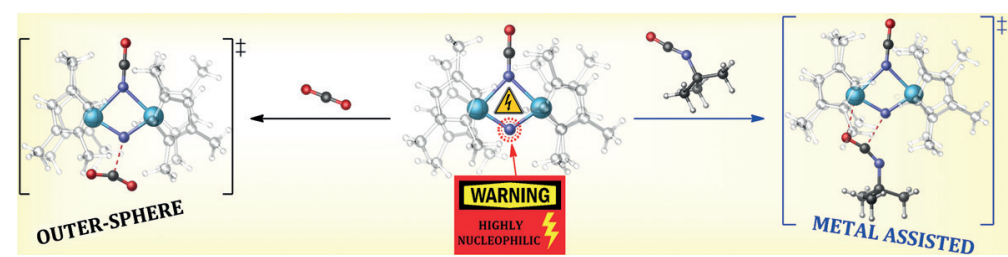

Nucleophilicity rules! A DFT mechanistic exploration of the reactivity of a dinitrogen hafnocene complex towards mixtures of $\mathrm{CO} / \mathrm{CO}_{2}$ and $\mathrm{CO} / \mathrm{OCN}$ Bu is reported. The crucial role of the nitride intermediate is highlighted, as well as the importance of the bridging mode of the cyanate ligand between the two Hf metal atoms.

\section{C-H Activation}

S. Ye, W. Yang, T. Coon, D. Fanning,

T. Neubert, D. Stamos,*

J.-Q. $Y u^{*}$ $4748-4752$

N-Heterocyclic Carbene LigandEnabled $\mathrm{C}\left(\mathrm{sp}^{3}\right)-\mathrm{H}$ Arylation of Piperidine and Tetrahydropyran Derivatives

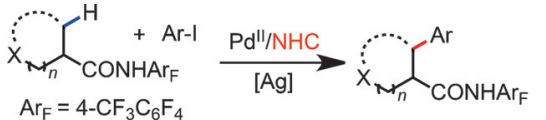

$\mathrm{Ar}_{\mathrm{F}}=4-\mathrm{CF}_{3} \mathrm{C}_{6} \mathrm{~F}_{4}$ $n=0-2$

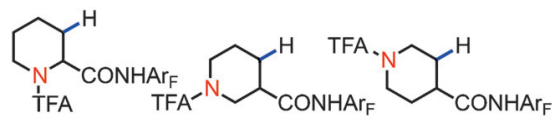<smiles>O=C(NC(F)F)C1CCOCC1C(=O)NC(F)F</smiles>

Pd"-catalyzed $\mathrm{C}\left(\mathrm{sp}^{3}\right)-\mathrm{H}$ arylation of saturated heterocycles with a wide range of aryl iodides is enabled by an $\mathrm{N}$-heterocyclic carbene (NHC) ligand. A $\mathrm{C}-\mathrm{H}$ insertion step by the $\mathrm{Pd} / \mathrm{NHC}$ complex in the absence of Arl is demonstrated experimentally for the first time. This arylation method provides a new approach for diversifying pharmaceutically relevant piperidine and tetrahydropyran ring systems (see scheme). 
Visible light-promoted decarboxylative di- and trifluoromethylthiolation of $1^{\circ}$, $2^{\circ}$, and $3^{\circ}$ alkyl carboxylic acids has been developed. The strategy employs electrophilic phthalimide-derived diand trifluoromethylthiolation reagents, with mechanistic studies suggesting the reaction involves a photoinitiated radical chain. The method features mild conditions, broad substrate scope and does not require additional oxidants.

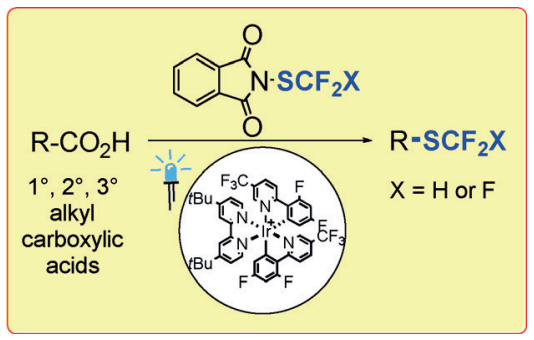

Photocatalysis

L. Candish, L. Pitzer, A. Gómez-Suárez,

F. Glorius*.... $4753-4756$

Visible Light-Promoted Decarboxylative Di- and Trifluoromethylthiolation of Alkyl Carboxylic Acids

\section{FULL PAPERS}

A germane substituent balance: A selective method for the synthesis of bis(pentafluoroethyl)germanium compounds is reported. The dibromogermane $\left(\mathrm{C}_{2} \mathrm{~F}_{5}\right)_{2} \mathrm{GeBr}_{2}$ reacts with $\mathrm{Ag}_{2} \mathrm{CO}_{3}$ to form the trigermoxane $\left[\left(\mathrm{C}_{2} \mathrm{~F}_{5}\right)_{2} \mathrm{GeO}\right]_{3}$ and with $\mathrm{Bu}_{3} \mathrm{SnH}$ to form the germane $\left(\mathrm{C}_{2} \mathrm{~F}_{5}\right)_{2} \mathrm{GeH}_{2}$.
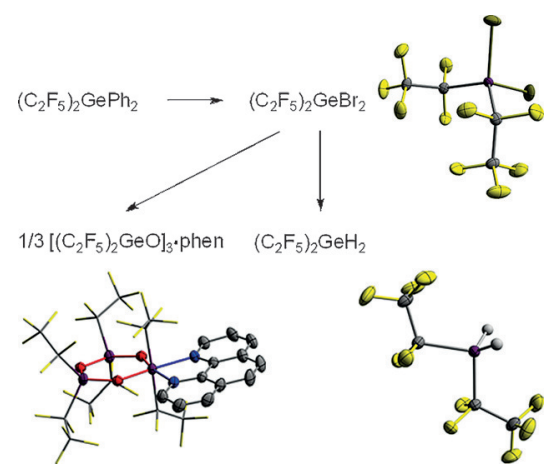

Main-Group Chemistry

S. Pelzer, B. Neumann, H.-G. Stammler, N. Ignat'ev, B. Hoge* $4758-4763$

Synthesis of Bis(pentafluoroethyl)germanes
$\operatorname{MoS}_{2} / C_{3} N_{4}$ heterojunction: A new type of graphene-like $\mathrm{MoS}_{2} / \mathrm{C}_{3} \mathrm{~N}_{4}$ composite has been prepared by a facile ethylene glycol-assisted solvothermal treatment. The synergistic effect of face-to-face combination increases the contact area and makes charge transfer more efficient, thereby promoting the separation of electron-hole pairs and leading to an enhancement of the overall photoconversion efficiency (see picture).

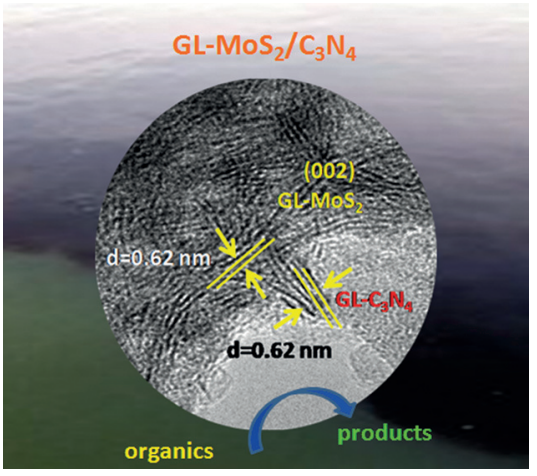

Graphene-Like Composites

J. Yan, Z. Chen, H. Ji, Z. Liu, X. Wang,

Y. Xu, X. She, L. Huang, L. Xu, H. Xu,*

H. $L i^{*}$. $4764-4773$

Construction of a 2D Graphene-Like $\mathrm{MoS}_{2} / \mathrm{C}_{3} \mathrm{~N}_{4}$ Heterojunction with Enhanced Visible-Light Photocatalytic Activity and Photoelectrochemical Activity

Front Cover
Double duty: The thermodynamics have been studied for the formation of double-stranded DNA (ds-DNA)-singlewalled carbon nanotube (SWNT) hybrids and exchange reactions of sodium cholate molecules on SWNTs and the ds-DNAs $d(A)_{20}-d(T)_{20}$ and nuclear factor (NF)- $\kappa \mathrm{B}$ decoy have been examined. In particular, $d(A)_{20}-d(T)_{20}$ shows a drastic change in its thermodynamic parameters around the melting temperature of the ds-DNA oligomer.

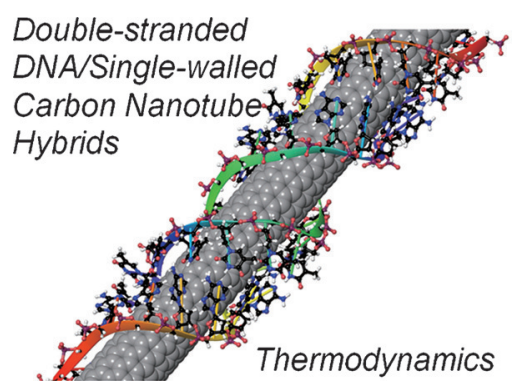

DNA

T. Shiraki, A. Tsuzuki, F. Toshimitsu,

N. Nakashima*............... 4774-4779

Thermodynamics for the Formation of Double-Stranded DNA-Single-Walled Carbon Nanotube Hybrids

Inside Cover 


\section{Perovskites}

A. Drag-Jarzabek, Ł. John, R. Petrus, M. Kosińska-Klähn,

P. Sobota*

$4780-4788$

Alkaline Earth Metal Zirconate Perovskites $\mathrm{MZrO}_{3}\left(\mathrm{M}=\mathrm{Ba}^{2+}, \mathrm{Sr}^{2+}\right.$, $\mathrm{Ca}^{2+}$ ) Derived from Molecular Precursors and Doped with $\mathrm{Eu}^{3+}$ Ions

Inside

Back Cover

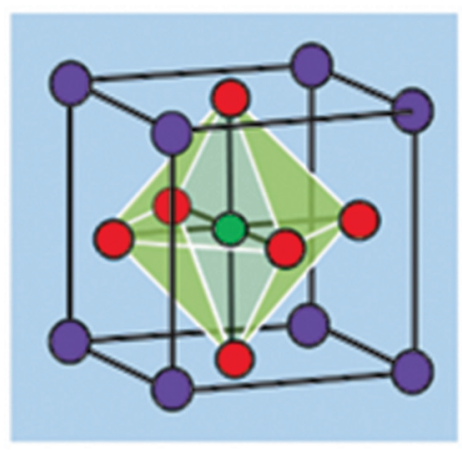

$\mathrm{MZrO}_{3}$
Molecular perovskite precursors: A simple, high-yield synthetic route for the preparation of single-source molecular precursors for preparing alkaline earth metal zirconate perovskites $\mathrm{MZrO}_{3}$ $(\mathrm{M}=\mathrm{Ba}$, $\mathrm{Sr}$, and $\mathrm{Ca}$; see figure), which were subsequently doped with $\mathrm{Eu}^{3+}$ ions, is presented. The $\mathrm{CaZrO}_{3}: \mathrm{Eu}^{3+}$ phosphor showed the highest luminescent intensity and is a highly promising candidate for applications in trichromatic white LEDs.
Nanotechnology

W. Z. Teo, R. Zboril, I. Medrik, M. Pumera* $4789-4793$

$\mathrm{Fe}^{0}$ Nanomotors in Ton Quantities ( $10^{20}$ Units) for Environmental Remediation

Back Cover

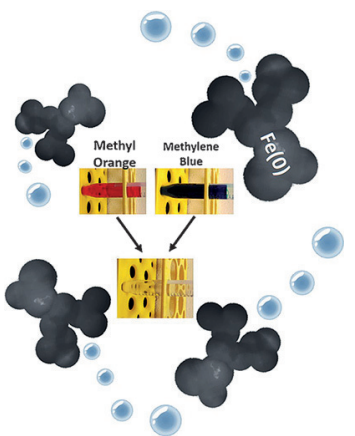

Decontamination agents: In view of the demand for large-scale environmental remediation by micro-/nanomotors, which are easily synthesized and powered by nontoxic fuel, bubble-propelled $\mathrm{Fe}^{0}$ Janus nanomotors have been developed by a facile thermally induced solid-state procedure and their potential as decontamination agents of pollutants investigated (see figure).

\section{Synthetic Methods}

M. J. Di Maso, K. M. Snyder,

F. De Souza Fernandes, O. Pattawong,

D. Q. Tan, J. C. Fettinger, P. H.-Y. Cheong, *

J. T. Shaw*...... $4794-4801$

Diastereoselective Synthesis of and Mechanistic Understanding for the Formation of 2-Piperidinones from Imines and Cyano-Substituted Anhydrides

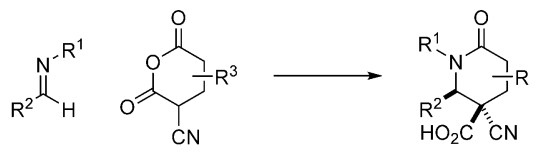

Mannich attack: 2-Piperidones are synthesized in a single step with up to three contiguous stereogenic centers.
- High diastereoselectivity

Quaternary stereogenic center

- Up to three contiguous stereogenic centers

- Orthogonal functionality at the quaternary stereogenic center

The transition states for these reactions are computed to probe the underlying causes for the stereochemical outcome.
Water Splitting

H. Chen, M. Lyu, G. Liu, *

L. Wang*.... $4802-4808$

Abnormal Cathodic Photocurrent Generated on an n-Type FeOOH Nanorod-Array Photoelectrode

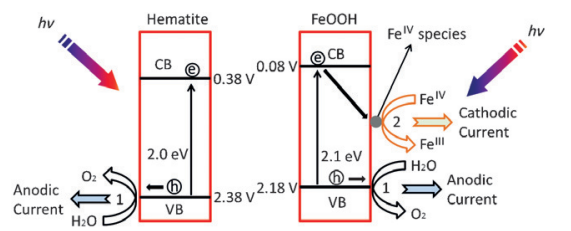

Cathodic adventures: An interesting abnormal cathodic photocurrent is generated on an n-type FeOOH/FTO photoelectrode. In contrast, the calcined hematite/FTO photoelectrode can only generate an anodic photocurrent (see scheme). Through detailed analysis, we surmise that the abnormal cathodic photocurrent may be related to a higher valence $\mathrm{Fe}^{\mathrm{IV}}$ species, which acts as an effective electron scavenger and thereby contributes to current generation. 
Radical cyclisation with aluminium aggregates! The radical cyclisation of $\alpha$-halo aluminium acetals has been studied in detail. Both monomeric and dimeric structures were found for these thermally labile aluminium acetals using ${ }^{13} \mathrm{C}$-INEPT DOSY experiments at low temperature and computational methods. The radical cyclisation was compared against the parent Ueno-Stork cyclisation, highlighting similarities and differences between the two reactions.

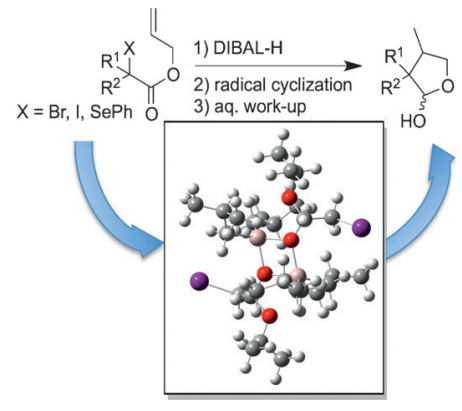

Radical Cyclisation

R. Bénéteau, A. Boussonnière,

J.-C. Rouaud, J. Lebreton, J. Graton,

D. Jacquemin, M. Sebban, H. Oulyadi,

G. Hamdoun, A. N. Hancock,

C. H. Schiesser, F. Dénès*..... 4809-4824

Radical Cyclisation of $\alpha$-Halo

Aluminium Acetals: A Mechanistic

Study

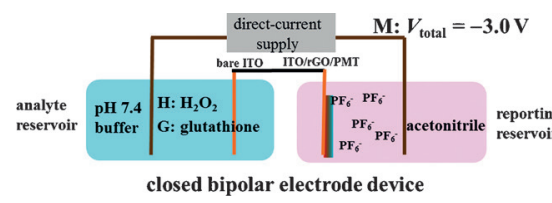

A keypad lock with $\mathrm{H}_{2} \mathrm{O}_{2}(\mathrm{H})$, glutathione $(\mathrm{G})$, and a driving voltage of $-3.0 \mathrm{~V}(\mathrm{M})$ as inputs, based on the closed bipolar electrode (BPE) system, and the color change of electrochromic

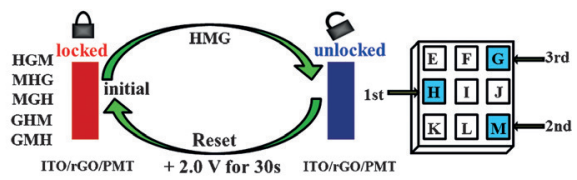

poly(3-methylthiophene) (PMT) films electropolymerized on the ITO electrode as the visible output was established (see figure). The security system could be reset and thus used repeatedly.
Molecular Devices

L. Wang, W. Lian, H. Liu*.... 4825-4832

A Resettable Keypad Lock with Visible Readout Based on Closed Bipolar Electrochemistry and Electrochromic Poly(3-methylthiophene) Films
Probing the $\mathrm{Xe}^{\mathrm{vl}}-\mathrm{N}$ bond: Theoretical calculations reveal that the $\mathrm{Xe}$ valence electron lone pairs of $\mathrm{F}_{6} \mathrm{XeNCCH}_{3}$ and $\mathrm{F}_{6} \mathrm{Xe}\left(\mathrm{NCCH}_{3}\right)_{2}$ are diffuse but stereochemically active, ineffectively shielding their Xe cores. The nitrogen base lone pairs coordinate to the resulting electrophilic sites, facing the Xe lone pair positions (see figure). The $\mathrm{Xe}-\mathrm{N}$ bonds are predominantly electrostatic and may be described as $\sigma$-hole interactions.

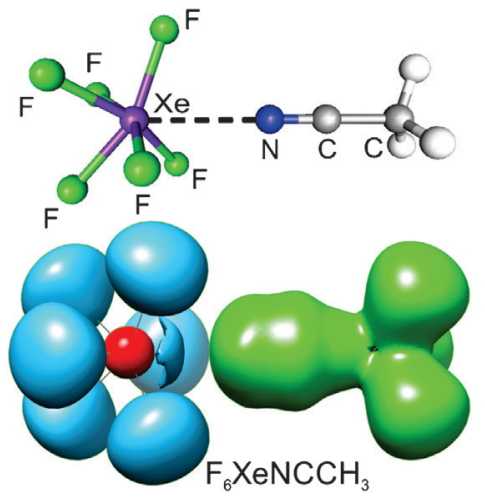

Xenon Fluorides

J. Haner, K. Matsumoto, H. P. A. Mercier, G. J. Schrobilgen* . $4833-4842$

Nature of the $\mathrm{Xe}^{\mathrm{v}}-\mathrm{N}$ Bonds in $\mathrm{F}_{6} \mathrm{XeNCCH}_{3}$ and $\mathrm{F}_{6} \mathrm{Xe}\left(\mathrm{NCCH}_{3}\right)_{2}$ and the Stereochemical Activity of Their Xenon Valence Electron Lone Pairs

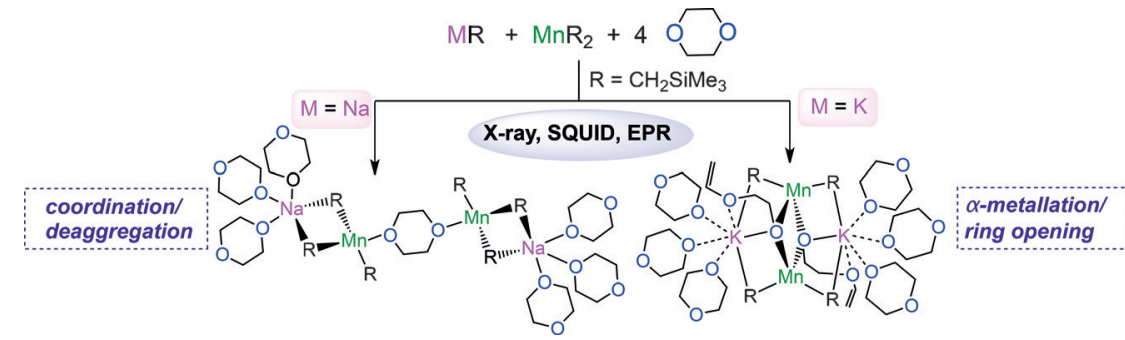

Heavy-metal influences: By exploring intriguing structural/synthetic/magnetic correlations in manganate chemistry, studies on the reactivity of tris(alkyl)manganates $\mathrm{MMnR}_{3}(\mathrm{M}=\mathrm{Na}, \mathrm{K}$;
$\mathrm{R}=\mathrm{CH}_{2} \mathrm{SiMe}_{3}$ ) towards Lewis bases have revealed that the outcome of these processes is controlled by the alkali metal present.
Manganate Complexes

M. Uzelac, I. Borilovic, M. Amores, T. Cadenbach, A. R. Kennedy, G. Aromi,*

E. Hevia* $4843-4854$

Structural and Magnetic Diversity in Alkali-Metal Manganate Chemistry: Evaluating Donor and Alkali-Metal Effects in Co-complexation Processes 


\section{Supramolecular Chemistry}

A. Inthasot, E. Brunetti, M. Lejeune, N. Menard, T. Prangé, L. Fusaro,

G. Bruylants, O. Reinaud, * M. Luhmer, ${ }^{*}$

I. Jabin, ${ }^{*}$ B. Colasson* $4855-4862$

Kinetic and Thermodynamic Stabilization of Metal Complexes by Introverted Coordination in a Calix[6]azacryptand

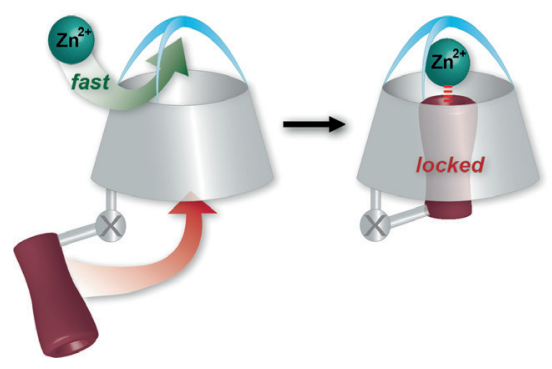

Introverted guest: A calix[6]arenebased azacryptand ligand bearing one additional amino-leg was selectively synthesized. Upon cation binding, this amino-leg occupies the cavity of the calixarene core. Such a coordination mode was fully characterized in solution and in the solid state for the $\mathrm{Zn}^{\text {" }}$ complex. The introverted coordination of the amino-leg allows for higher kinetic and thermodynamic stabilities (see figure).
Nanomaterials

X. Wang, P. Zhang, W. Wang, X. Lei, H. Yang* $4863-4869$

Magnetic N-Enriched $\mathrm{Fe}_{3} \mathrm{C} /$ Graphitic Carbon instead of $\mathrm{Pt}$ as an Electrocatalyst for the Oxygen Reduction Reaction

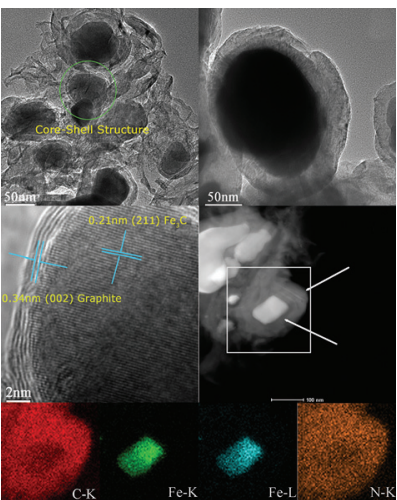

Magnetic nanomaterials: A series of $\mathrm{Fe}_{3} \mathrm{C} / \mathrm{C}-\mathrm{N}_{\mathrm{x}}$ nanoparticles (NPs) with different nitrogen content are prepared by a simple one-pot route (see figure). The materials exhibit excellent magnetic properties and oxygen reduction reaction (ORR) activities.

\section{Metal-Organic Frameworks}

R. J. Marshall, S. L. Griffin, C. Wilson, O R.S. Forgan* $4870-4877$

Stereoselective Halogenation of Integral Unsaturated C-C Bonds in Chemically and Mechanically Robust $\mathrm{Zr}$ and Hf MOFs

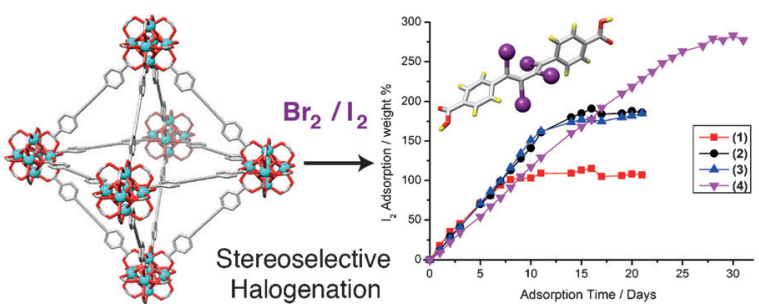

lo-dining out: The combined chemical and mechanical stabilities of $\mathrm{Zr}$ and $\mathrm{Hf}$ metal-organic frameworks facilitate their stereoselective postsynthetic halogenation across integral unsaturated bonds, in some cases reversibly, leading to a material that can ingest $279 \% \mathrm{w} / \mathrm{W}$ $\mathrm{I}_{2}$ by a combination of chemi- and physisorption.

\section{Through-Bond Coupling}

Y. Tsuji, R. Hoffmann* $4878-4888$

Helical Oligoenes: Conformations, Bond Alternation, and Competing Through-Bond and Through-Space Transmission

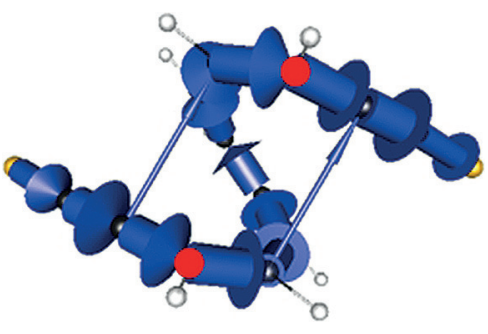

The structures of and electron transport through helical oligoenes were studied theoretically to determine whether the dominant transport mechanism is through-space or through-bond. A range of almost equal energy structures for all- $Z$ all-s-cis tetraene, pentaene, and hexaene varying in helix pitch was found. An intramolecular orbital interaction stabilizes a more compact conformation in the longer helical oligoenes. 
Delayed fluorescence: Because of thermal spin upconversion of donoracceptor molecules, efficient electrogenerated chemiluminescence (ECL) was realized (see figure; ISC: intersystem crossing, RISC: reverse intersystem crossing). Moreover, methyl, tert-butyl, and phenyl substituents on the donoracceptor molecule enhance the ECL stability.

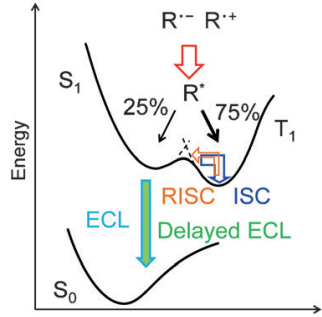

Electrochemiluminescence

R. Ishimatsu, * T. Edura, C. Adachi, ${ }^{*}$

K. Nakano, T. Imato* ......... 4889-4898

Photophysical Properties and Efficient, Stable, Electrogenerated Chemiluminescence of Donor-Acceptor Molecules Exhibiting Thermal Spin Upconversion

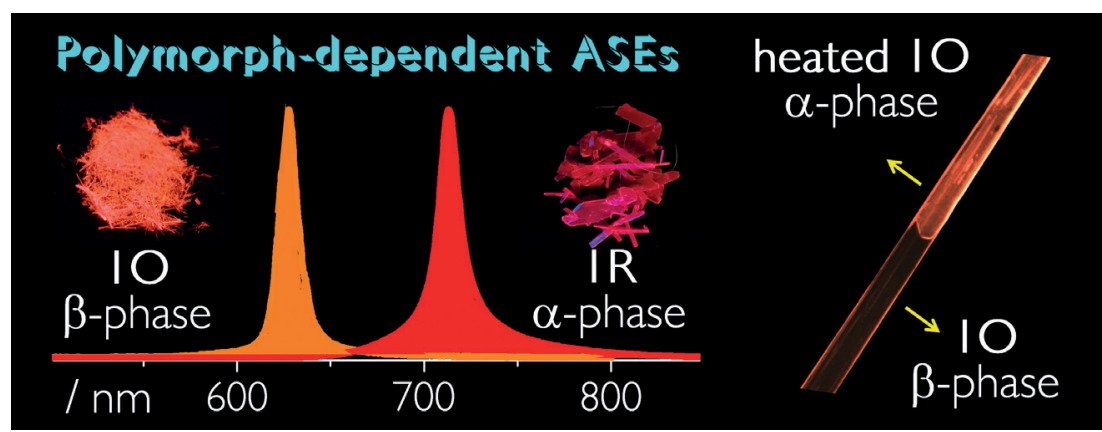

Two organic polymorphs with near-IR (1R: $\alpha$-phase) and orange-red (10: $\beta$-phase) emissions were synthesized based on a structurally simple organic molecule that undergoes excited-state intramolecular proton transfer. 10 can transform into the $\alpha$ phase accompanied with an unprecedented amplified spontaneous emmision changing in a single-crystal to single-crystal manner.
Crystal Engineering

X. Cheng, Y. Zhang, S. Han, F. Li,

H. Zhang, ${ }^{*}$ Y. Wang ........... 4899-4903

Multicolor Amplified Spontaneous Emissions Based on Organic Polymorphs That Undergo ExcitedState Intramolecular Proton Transfer

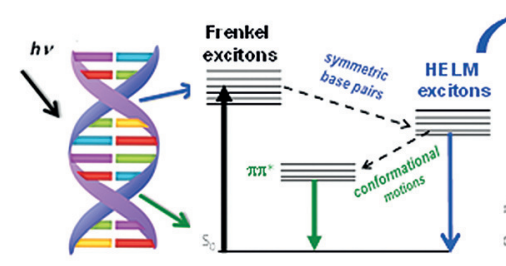

High-energy long-lived mixed (HELM) excitons are populated during excitedstate relaxation in $(\mathrm{AT})_{n}$ duplexes. They result from mixing between Frenkel excitons and adenine-to-thymine charge-transfer states and extend over

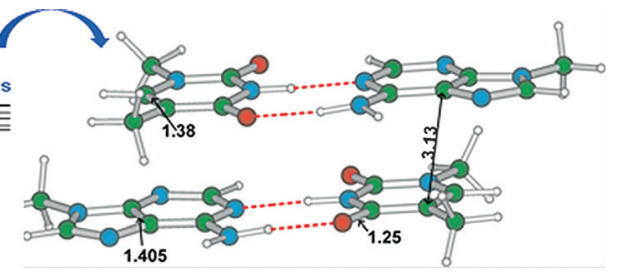
properties of HELM states (high emission energy, low fluorescence anisotropy, nanosecond lifetime, and sensitivity to conformational disorder) are also detected for natural DNA. at least four bases on both strands. The

DNA Fluorescence

I. Vayá, J. Brazard, M. Huix-Rotllant, A. K. Thazhathveetil, F. D. Lewis,*

T. Gustavsson, I. Burghardt, R. Improta, ${ }^{*}$

D. Markovitsi* ................. 4904-4914

High-Energy Long-Lived Mixed Frenkel-Charge-Transfer Excitons: From Double Stranded $(\text { AT })_{n}$ to Natural DNA

Multitasking: The in situ encapsulation of $\mathrm{SnO}_{2}$ nanoparticles in an ordered mesoporous carbon (OMC) framework results in the formation of a high-performing anode material suitable for use in lithium-ion batteries. Within this composite the OMC acts as multifunctional matrix (see figure; EISA = evaporationinduced self-assembly).
Batteries

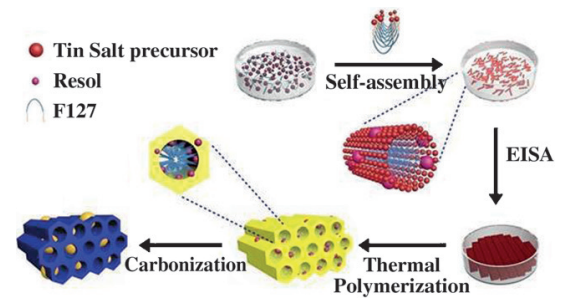

H. Xue, J. Zhao, J. Tang, H. Gong, P. He, H. Zhou, * Y. Yamauchi,*

J. $H e^{*} \ldots \ldots \ldots \ldots \ldots \ldots \ldots \ldots . . . . .24915-4923$

High-Loading Nano-SnO $\mathrm{O}_{2}$ Encapsulated in situ in Three-Dimensional Rigid Porous Carbon for Superior Lithium-Ion Batteries 


\section{Liquid Crystals}

H. Blanco, V. lguarbe, J. Barberá,

J. L. Serrano, A. Elduque,*

R. Giménez*

$4924-4930$

Supramolecular Columnar Liquid Crystals with Tapered-Shape Simple Pyrazoles Obtained by Efficient Henry/ Michael Reactions

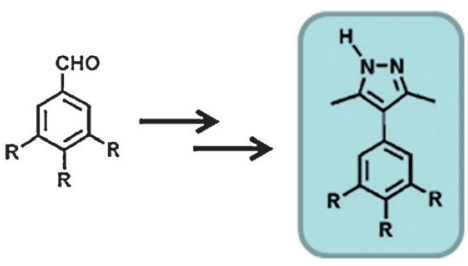

Tapered liquid crystals: A straightforward synthesis of pyrazoles leads to novel supramolecular synthons able to

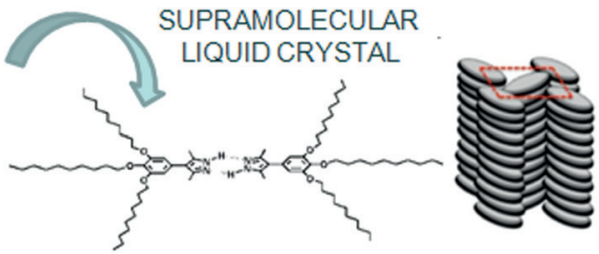

self-assemble in soft columnar organizations.
Covalent Organic Frameworks

A. Karmakar, A. Kumar, A. K. Chaudhari,

P. Samanta, A. V. Desai, R. Krishna,

S. K. Ghosh* $4931-4937$

Bimodal Functionality in a Porous Covalent Triazine Framework by Rational Integration of an ElectronRich and -Deficient Pore Surface

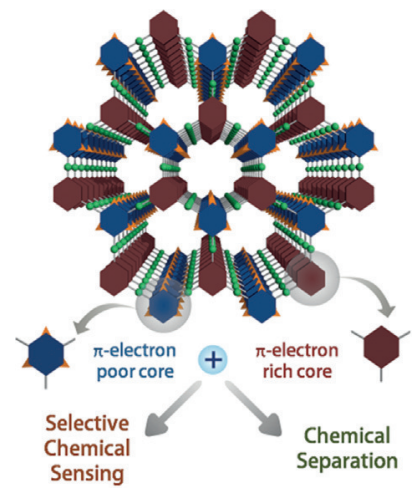

Best of both worlds: A porous covalent triazine framework consisting of both an electron-deficient central triazine core and electron-rich aromatic building blocks is reported. The electron deficiency in the central core was utilized to separate benzene from cyclohexane. By virtue of the electron-rich aromatic rings with Lewis basic sites, aqueous phase chemical sensing of highly explosive 2,4,6-trinitrophenol was achieved.
Pauson-Khand Reactions

A. Tap, C. Lecourt, S. Dhambri,

M. Arnould, G. Galvani,

O. Nguyen Van Buu, M. Jouanneau,

J.-P. Férézou, J. Ardisson, M.-I. Lannou,*

G. Sorin* $4938-4944$

Alkoxyallene-ynes: Selective Preparation of Bicyclo[5.3.0] Ring Systems Including a $\delta$-Alkoxy Cyclopentadienone
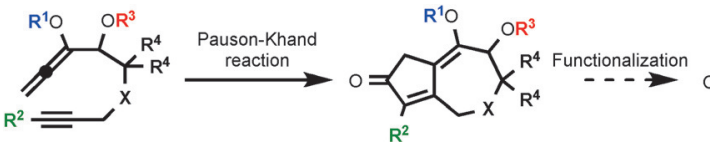<smiles>CC1C(=O)CC2C1CCCCC2(C)O</smiles>
$\mathrm{x}=\mathrm{T}_{\mathrm{O}}, \mathrm{NTs}, \mathrm{O}$

Guaiane skeleton with a tertiary alcohol at $\mathrm{C} 10$

Guaiane skeleton synthesis: Intramolecular rhodium-catalyzed PausonKhand cyclocarbonylation reactions of alkoxyallene-ynes with the alkoxy group at the proximal position were successfully performed to access $[5,7]$ ring systems bearing an enol ether. This procedure offers a straightforward access to guaiane skeletons with a tertiary hydroxy group at the C10 position (see scheme; Ts= toluene-4-sulfonyl).

\section{Ring Rearrangements}

J. Dolfen, K. Vervisch, N. De Kimpe, M. D'hooghe* $4945-4951$

$\mathrm{LiAlH}_{4}$-Induced Selective Ring Rearrangement of 2-(2-Cyanoethyl)aziridines toward 2-(Aminomethyl)pyrrolidines and 3-Aminopiperidines as Eligible Heterocyclic Building Blocks

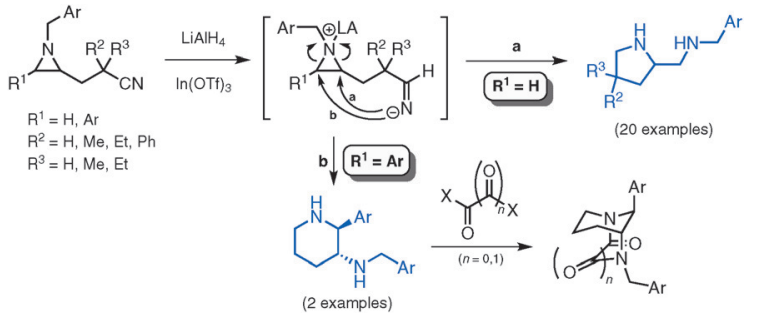

A novel $\ln (\mathrm{OTf})_{3}$-promoted reductive ring transformation of 2- and 3-(2-cyanoethyl)aziridines is disclosed, providing access to either 2-(aminomethyl)pyrrolidines or 3-aminopiperidines in a regio- and stereoselective way. The obtained diamines were further transformed into new (constrained) bicyclic imidazolidinone and diketopiperazine scaffolds (see scheme, LA = Lewis acid). 


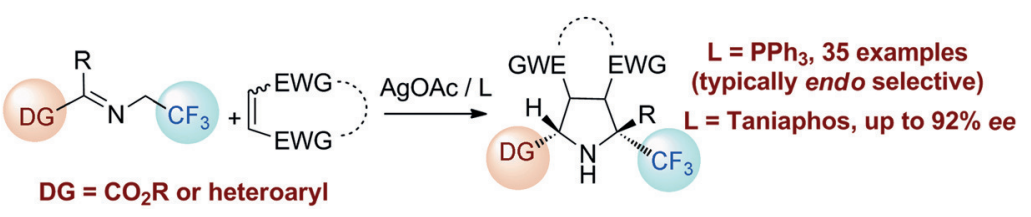

Fluorinated pyrrolidines: An efficient silver-catalyzed 1,3-dipolar cycloaddition of fluorinated azomethine ylides with activated olefins is reported. A wide variety of fluorinated pyrrolidines were obtained under simple reaction conditions with high yields and high levels of diastereoselectivity. The high reactivity observed in the cycloaddition relies on the presence of a metal-coordinating moiety, such as an ester or heteroaryl group, on the azomethine ylide precursor.
Asymmetric Catalysis

A. Ponce, I. Alonso, J. Adrio,*

J. C. Carretero* ............... $4952-4959$

Stereoselective Ag-Catalyzed

1,3-Dipolar Cycloaddition of Activated Trifluoromethyl-Substituted Azomethine Ylides
Pt-Cu nanoframes were produced from copper nanoparticles by a one-pot synthesis. The growth mechanism was thoroughly studied by experiment and theoretical calculations. Owing to the unique structure, Pt-Cu nanoframes exhibited significantly enhanced catalytic activity toward the electro-oxidation of methanol compared to commercial Pt black.

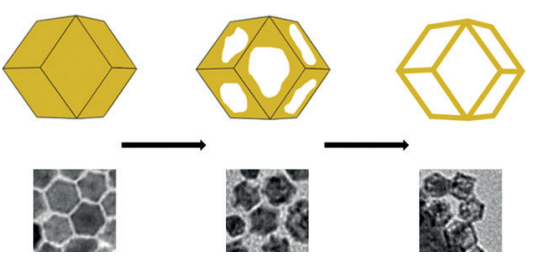

Nanomaterials

X. Yu, L. Li, Y. Su, W. Jia, L. Dong,

D. Wang, ${ }^{*}$ J. Zhao, ${ }^{*}$ Y. Li .... $4960-4965$

Platinum-Copper Nanoframes: OnePot Synthesis and Enhanced Electrocatalytic Activity
Dig for fire: 1-Nitraminobitetrazoles are a class of very high performance explosive materials with potential application as heavy-metal-free primary explosives. Now the corresponding 1-nitraminoazobitetrazoles, which are even more powerful but also more sensitive, have been synthesized.

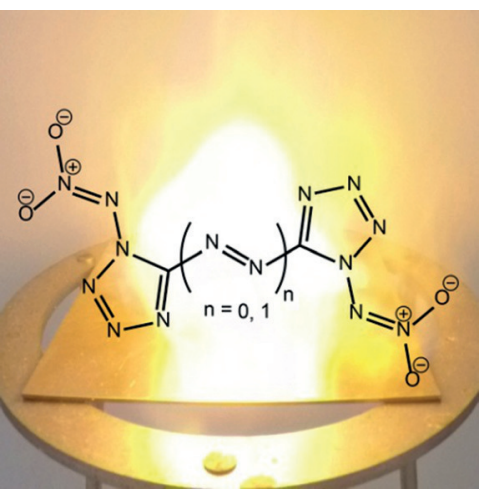

Energetic Materials

D. Fischer, T. M. Klapötke, ${ }^{*}$ J. Stierstorfer, N. Szimhardt. $4966-4970$

1,1'-Nitramino-5,5'-bitetrazoles
Electronic give-and-take: Mono- and di-porphyrin-aza-BODIPY architectures (see figure) have been synthesized. A comprehensive photophysical study of these polyads has revealed a predominantly electron-rich character of the porphyrin peripheries, as opposed to the highly electron-accepting azaBODIPY core, leading to charge separation in the excited state.

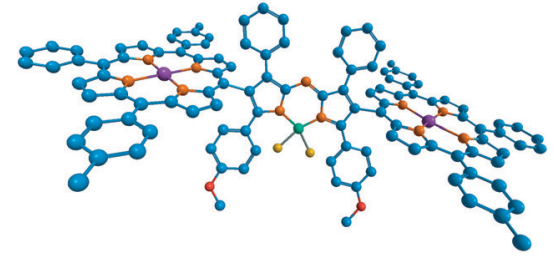

Fluorescence Spectroscopy

S. Pascal, L. Bucher, N. Desbois, C. Bucher, C. Andraud, ${ }^{*}$ C. P. Gros* ..... $4971-4979$

Synthesis, Electrochemistry, and Photophysics of Aza-BODIPY Porphyrin Dyes
Halogen-assisted dendritic organogels: A new class of poly(benzyl ether) dendrons with halo substituents decorating their periphery (see figure) was synthesized and fully characterized. They exhibited pronounced halogensubstituent effects on their organogelation properties.

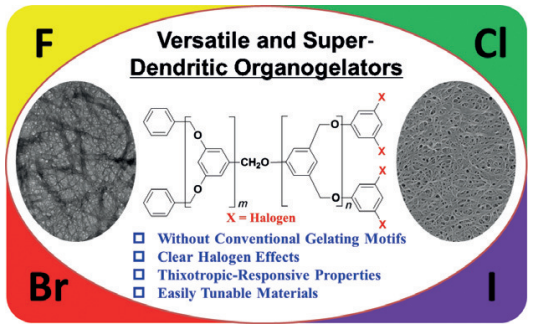

Gelators

Y. Feng, ${ }^{*}$ H. Chen, Z.-X. Liu, Y.-M. He, Q.-H. Fan ...................... $4980-4990$

A Pronounced Halogen Effect on the Organogelation Properties of Peripherally Halogen Functionalized Poly(benzyl ether) Dendrons 


\section{Synthesis Design}

R. Adam, E. Alberico, W. Baumann,

H.-J. Drexler, R. Jackstell, H. Junge,

M. Beller*

$4991-5002$

NNP-Type Pincer Imidazolylphosphine

Ruthenium Complexes: Efficient BaseFree Hydrogenation of Aromatic and Aliphatic Nitriles under Mild Conditions

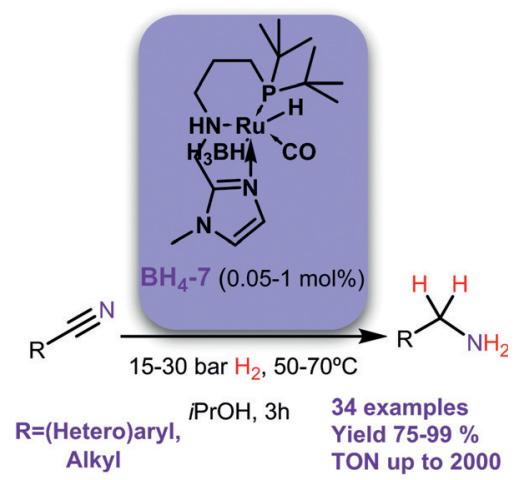

Alkyl $\quad$ TON up to 2000

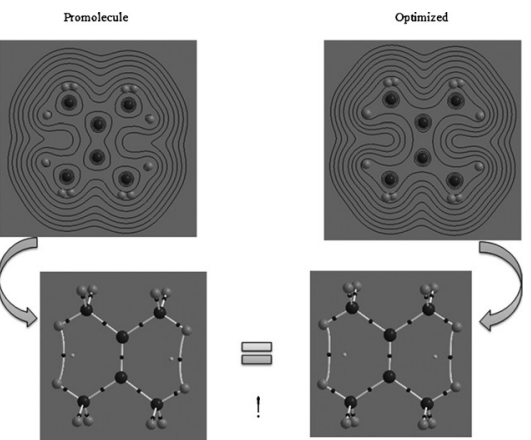

In a pinch: A new family of ruthenium phosphineimidazolyl complexes is presented and their activity in the hydrogenation of nitriles investigated. Among those tested, complex $\mathrm{BH}_{4} \mathbf{- 7}$ (see scheme) turned out to be highly active and was able to hydrogenate several (hetero)aromatic and aliphatic nitriles, including adiponitrile, under mild conditions.

Equivalent densities: The molecular graphs (MGs) emerging from the topological analysis of ab initio-derived molecular electron densities are equal to the MGs emerging from the promolecule electron densities (see figure). This suggests, in contrast to the widespread view, that the topology of the molecular electron density does not reflect chemical bonds or strong interactions between atoms in hydrocarbons.

\section{Reaction Mechanisms}

J. Zhang,* J. Xie, M. E. Lee, L. Zhang, Y. Zuo, S. Feng $5010-5016$

Ionic $\mathrm{S}_{\mathrm{N}} \mathrm{i}$-Si Nucleophilic Substitution in $\mathrm{N}$-Methylaniline-Induced $\mathrm{Si}-\mathrm{Si}$ Bond Cleavages of $\mathrm{Si}_{2} \mathrm{Cl}_{6}$

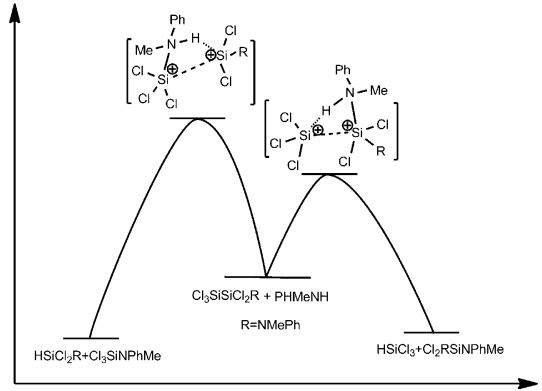

Silicon behavior: Based on theoretical studies, a new ionic $\mathrm{S}_{\mathrm{N}} \mathrm{i}-\mathrm{Si}$ nucleophilic substitution mechanism is introduced for the $\mathrm{N}$-methylaniline-induced $\mathrm{Si}-\mathrm{Si}$ bond cleavage in $\mathrm{Si}_{2} \mathrm{Cl}_{6}$ (see figure). The mechanism explains the experimental results very well.
* Author to whom correspondence should be addressed.

$\square$ Supporting information on the WWW (see article for access details).

69 A video clip is available as Supporting Information on the WWW (see article for access details).

0 This article is available online free of charge (Open Access).
IP Articles labeled with this symbol have been judged by two referees as being "very important papers".

(4) Hot Papers are articles that Editors have chosen on the basis of referee reports to be of particular importance for an intensely studied area of research.

20 Editorial Board Member contribution to celebrate the $20^{\text {th }}$ anniversary of the journal.

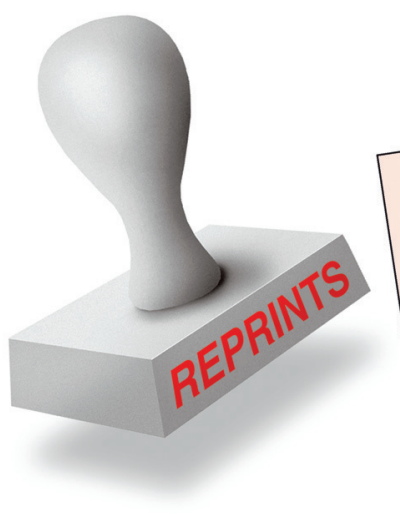

Fast, Individual, Popula REPRINTS Available to order any-reprint@@wiley.com) 